\title{
Experimental research of two stroke aircraft diesel engine
}

\begin{abstract}
This paper presents the results of experimental studies of the opposed-piston diesel engine. This engine was designed during one of the stages of the research on a new-type drive unit for gyrocopter applications. In order to conduct research, a special test stand as well as control and measurement systems were developed. As part of the work on the engine, the fuel injection system, engine temperature control system and measurement systems were designed. In addition, a computer program has been developed for the fuel injection system control (injectors, valves fuel pressure regulators). The paper presents the results of the preliminary tests for a single value of engine speed (1500 rpm) and three values of load defined by torque. The measured value of the indicated pressure made it possible to calculate the maximum pressure. The results obtained from the bench tests were analyzed.
\end{abstract}

Key words: diesel, engine, indicated pressure, opposed-piston, two-stroke

\section{Introduction}

Spark ignition engines are widely used for propulsion of light aircrafts. In recent years, several diesel models (Thielert, SMA Engines) have appeared on the aviation market, which effectively compete in this field with SI engines. The innovative solution is the use of two-stroke opposed-piston diesel engine for propulsion of aircraft. A completely new type of propulsion requires a series of tests of such an engine.

The basic method of testing internal combustion engines are workplace tests using an electric brake and a set of measuring sensors. One of the key measurement signals in the engine test stands is the pressure signal in the cylinder. It can be used to create an open indicator graph. A comparison of a number of such ranges for subsequent work cycles allows for the creation of a dense indicator diagram. Its analysis makes it possible to assess the phenomenon of the uniqueness of subsequent work cycles, which may result from unequal filling of the cylinder with a fresh charge or an uneven combustion process. In addition, the pressure signal in the cylinder allows for a series of additional analyzes: combustion process, heat load and heat efficiency, mechanical load. On the basis of the pressure data for the gas in cylinder it is also possible to calculate the work performed by the gas acting on the piston [1]. Many publications focus on the analysis of the combustion process using cylinder pressure. a method for performing a quick thermodynamic diagnosis of the combustion process in a DI diesel engine. Pressure signal analysis in time and time-frequency do-mains can be used for detecting the start and the end of combustion and the heat release peak [3]. Moreover, the misfire phenomenon can be detected using the pressure cylinder signal [4]. The analysis of cylinder pressure allows for the investigation of start of combustion and calculation of an accurate net rate of heat release indicator diagram in the case of the dual-fuel engines study [5]. The cylinder pressure signal can also be used to analyze the noise of working engine. An example is work [6], in which the method of analyzing noise generated during the combustion process in a diesel engine was presented. A similar issue was analyzed in the paper [7]. The pressure cylinder can be used to control the operation of the engine. This method was analyzed in the paper [8], which presents the control of the closed-loop combustion process using the digital cylinder pressure signal in a diesel engine. A similar solution was analyzed in the paper [9], where the cylinder pressurebased control system (CPBC) for conventional diesel combustion with high EGR levels was used. The authors of the paper [10] presented the use of cylinder pressure to control pre-mixed diesel combustion. The authors paid attention to the control effectiveness of the real-time cylinder pressure feedback.

In order to obtain an indicator diagram it is necessary to use the following devices: a pressure sensor placed in the cylinder, a position sensor of the crankshaft and a recorder. The direct application of the pressure transducer in the cylinder is limited for technical and economic reasons. Direct measurement requires a high-performance pressure transmitter capable of withstanding the difficult operating conditions inside the cylinder. Flame front transducers are expensive, have a limited lifetime and require some modifications to the design of the engine for their installation [11]. The authors of the publication [11] introduced the nonparametric modelling techniques to reconstruct the cylinder pressure in the diesel engine. In paper [12], an attempt was made to reproduce the cylinder pressure signal based on externally measured engine vibration signal.

The cylinder pressure signal can also be used to analyze exhaust emissions. In [13], a neural network was used to predict emissions of the direct injection diesel engine. The authors of the paper [14] presented a method of real-time estimation of engine-out particulate matter emissions of a diesel engine using in-cylinder pressure signal.

The purpose of the research was to conduct a preliminary analysis of the unevenness of work of the newlydesigned two-stroke opposed-piston diesel engine. For this purpose, experimental tests were performed on a test bench. For the defined operating points, the value of pressure as a function of time was obtained in one of the cylinders of the tested engine. The registered signal was used to perform the analysis of work uniformity. For the defined operating points, a statistical analysis was performed and the average value of the maximum cylinder pressure was calculated. In 
addition, based on the calculated $\mathrm{p}_{\max }$ values, return maps for the defined operating points were developed.

\section{Research object and test stand}

The tests were performed using a test bench located in the laboratory of the Lublin University of Technology. The basic element of test stand is the Electromyron EMX 100/10000 electric brake. Table 1 shows the basic brake data. The engine was connected to the brake by means of a shaft and an overload clutch. The test object was two-stroke opposed piston diesel engine.

Table 1. Technical data of the EMX-100 brake

\begin{tabular}{|l|c|}
\hline Brake type & EMX-100/10000 \\
\hline Maximum power & $100 \mathrm{~kW}$ \\
\hline Maximum speed & $10000 \mathrm{rpm}$ \\
\hline Maximum torque & $240 \mathrm{Nm}$ \\
\hline Brake mass & $250 \mathrm{~kg}$ \\
\hline Turning direction & any \\
\hline Length of the measuring arm & $0.370 \mathrm{~m}$ \\
\hline
\end{tabular}

This engine is a development version of a new construction designed for propelling ultra-light aircraft. The engine is called PZL 100 and can generate $100 \mathrm{~kW}$ of power. The basic design and functional assumptions for the engine are summarized in Table 2. The engine in the development version is shown in Fig. 1.

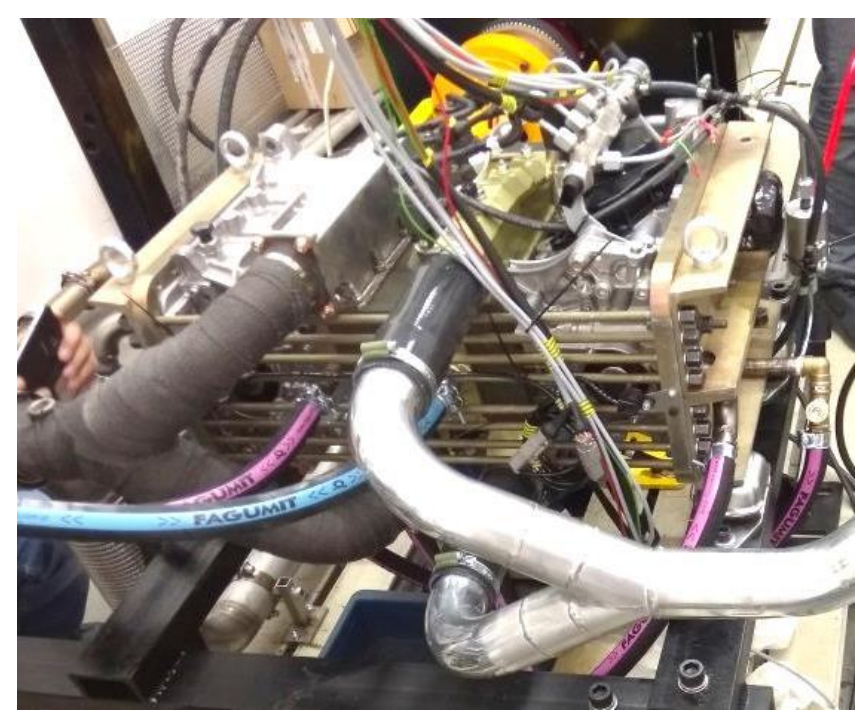

Fig. 1. PZL 100 engine on the test bench

Table 2. Basic parameters of the research object

\begin{tabular}{|l|c|}
\hline Take off power & $100 \mathrm{~kW}$ \\
\hline Engine speed & $4200 \mathrm{rpm}$ \\
\hline Number of cylinders & 3 \\
\hline Bore & $65.5 \mathrm{~mm}$ \\
\hline Stroke & $72 \mathrm{~mm}$ \\
\hline Compression ratio & $22: 1$ \\
\hline Scavenging & Uniflow \\
\hline
\end{tabular}

As part of the tests, the pressure in the combustion chamber of the first cylinder was measured. The engine has been equipped with a pressure measuring system located in the first cylinder. For this purpose, a mounting socket was made in the engine block and cylinder liner in accordance with the pressure sensor manufacturer's instructions. The GH14D sensor from AVL was used to measure the pressure. The sensor is shown in Fig. 2. It is a piezo-electric sensor with a measuring range of 0-25 $\mathrm{MPa}$. Signal conditioning was performed with the AVL MICRO IFEM piezo 4CH SDC amplifier.

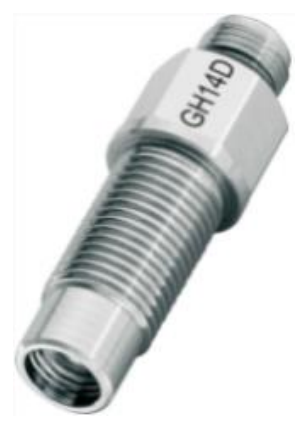

Fig. 2. GH14D pressure sensor

In addition, a program for controlling the fuel injection process was developed (using injectors and valves controlling the fuel pressure). The window of the developed program is shown in Fig. 3. The engine is equipped with two injectors per cylinder. This solution reduces the time of fuel injection and enables precise distribution of fuel in the combustion chamber. The PZL 100 engine control system was made at Expansion Chassis from National Instruments. It is a device designed for controlling and collecting data, based on the Zynq-7020 FPGA chip. The platform used has a built-in network interface that allows remote communication with the device. For testing the engine, a program was developed in the LabView software from National Instruments. Due to the need for precise control of injectors and synchronization of the moment of injection occurrence with the position of the crankshaft, the program had to consist of two modules. The first module was responsible for the synchronization and communication of the measuring card with the executive card. The second module was written in the LabVIEW RT software, which is used to create applications that work in real time.

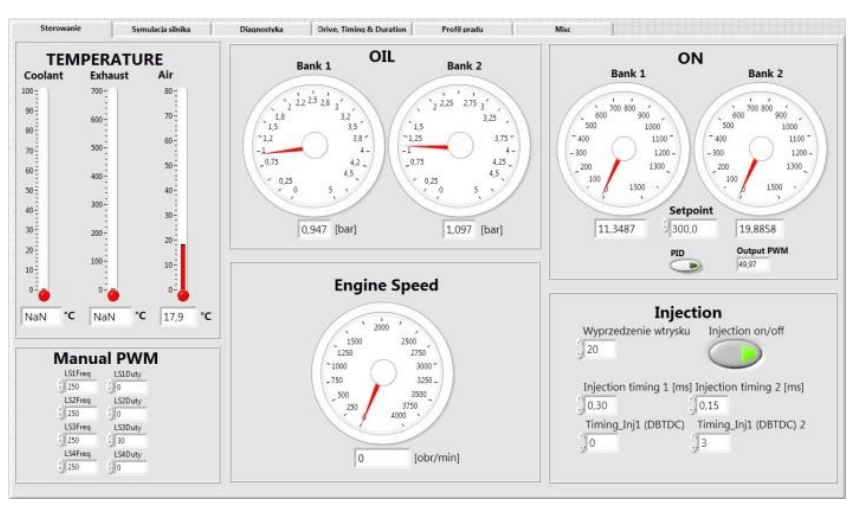

Fig. 3. The engine control panel window

The developed program allowed to set parameters such as: - oil pressure in fuel rails,

- advance injection in relation to TDC (expressed in crank angle), 
- duration of the first injection,

- duration of the second injection,

- offset of the next injection in relation to the previous one.

The results were recorded using the National Instruments 9215 measuring card. A program was also developed in the LabView environment. During the tests, a sampling and recording frequency of $100,000 \mathrm{~Hz}$ was adopted. The indicated pressure in the first cylinder and the crankshaft position signal were recorded.

\section{Experimental results}

The conducted tests were preliminary tests performed after the first start of a new engine type. The purpose of the research was to conduct a basic analysis of the unevenness of engine work. Therefore, the tests were carried out at low values of the rotational speed and the load determined by the torque. For the defined speed value, the power generated was increased by increasing the fuel dose. This is confirmed by the value of the air-fuel equivalence ratio $\lambda$ shown in Table 3. The lambda value was measured in the exhaust system.

Table 3. Defined engine operating parameters

\begin{tabular}{|c|c|c|c|}
\hline No. & $\mathrm{N}[\mathrm{rpm}]$ & $\mathrm{M}[\mathrm{Nm}]$ & $\lambda[-]$ \\
\hline 1 & 1500 & 11 & 4,5 \\
\hline 2 & 1500 & 22 & 3,8 \\
\hline 3 & 1500 & 31 & 2,9 \\
\hline
\end{tabular}

Due to the interference, the signal was subjected to filtration. A low-pass filter was used that removed the frequency bands below $15,000 \mathrm{~Hz}$. The result of this process is presented in Fig. 4. Then the signal was converted using a factor of $25.00758 \mathrm{bar} / \mathrm{V}$. The time of one cycle for the analyzed operating points was $40 \mathrm{~ms}$ at the engine speed equal to $1500 \mathrm{rpm}$. During engine operation for the fuel injection that initiated the combustion, the injector opened at $0.4 \mathrm{~ms}\left(20^{\circ}\right.$ before TDC). The main injection was given $4^{\circ}$ before TDC, and the injector opened at $0.5 \mathrm{~ms}, 0.7 \mathrm{~ms}$, $0.9 \mathrm{~ms}$, respectively for three measuring points according to Table 3. The obtained $p_{\max }$ values were subjected to statistical analysis, specifying average values and standard deviations.

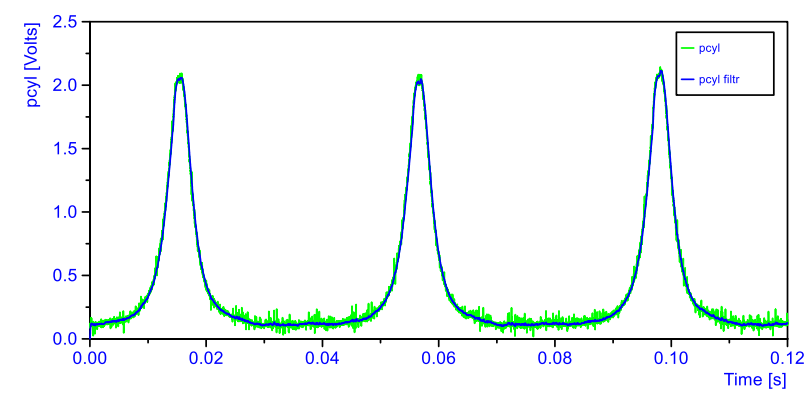

Fig. 4. The signal from the pressure sensor in the first cylinder

Figures 5-7 show cylinder pressure as a function of time for 12 consecutive work cycles for defined operating points. The maximum pressure in the cylinder that was registered was equal to 57.19 bar. Analyzing consecutive maxima for the three operating points, a significant pressure fluctuation can be observed.

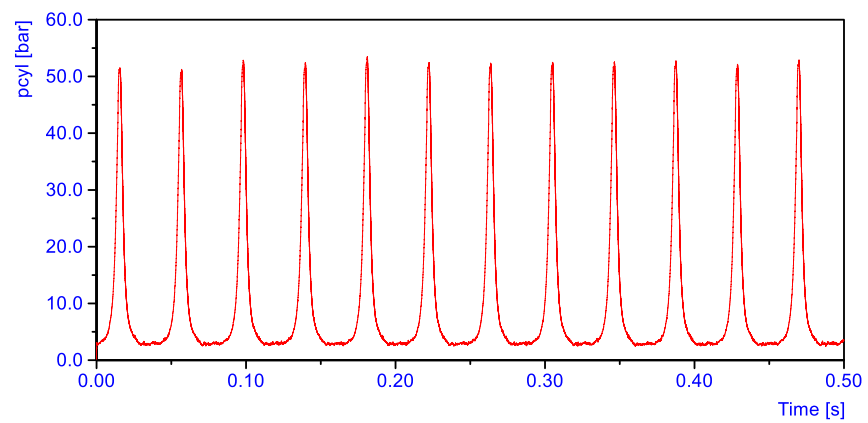

Fig. 5. Fragment of the pressure in the first cylinder - operating point No. 1

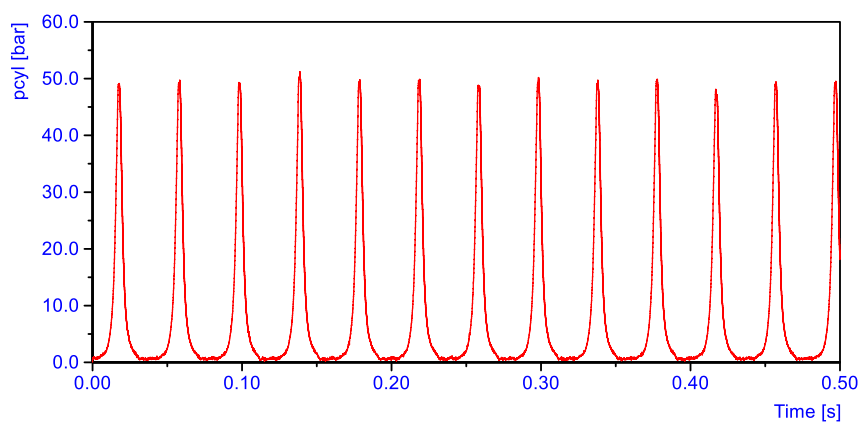

Fig. 6. Fragment of the pressure in the first cylinder - operating point No. 2

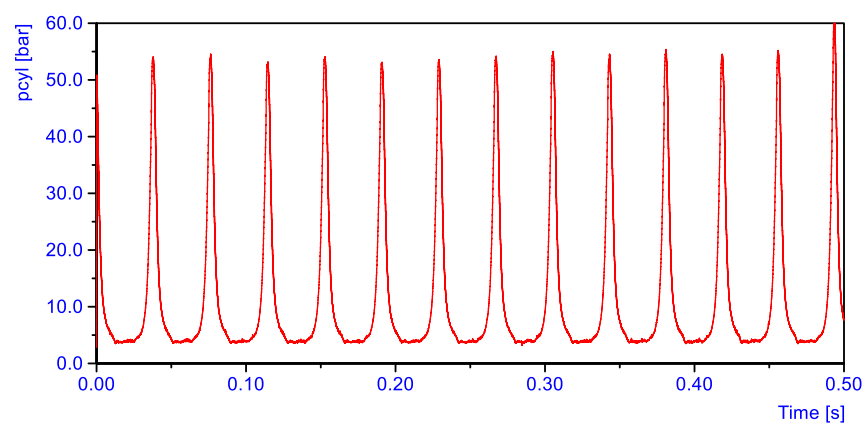

Fig. 7. Fragment of the pressure in the first cylinder - operating point No. 3

Figures 8-10 show calculated maximum cylinder pressure as a function of time for defined operating points. The time of recording pressure signal was 32 seconds for all analyzed work points.

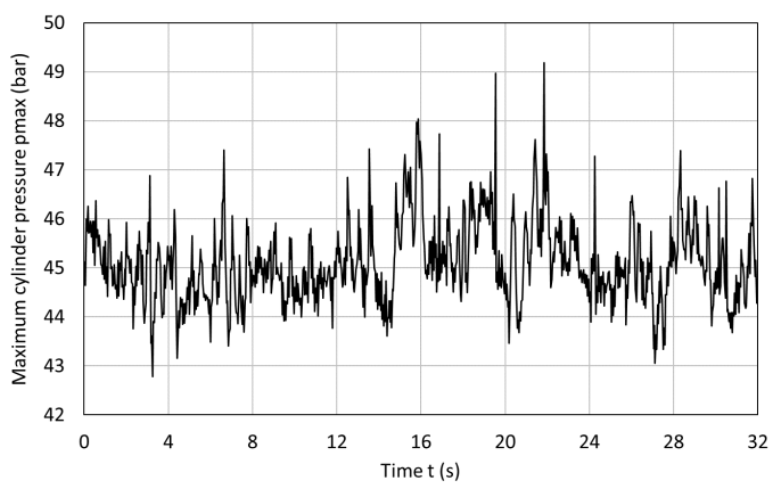

Fig. 8. Maximum cylinder pressure for operating point No. 1 
Even in the case of the smallest load there was a significant fluctuation in cylinder pressure. For this working point its value varied from 42.78 to 49.18 bar.

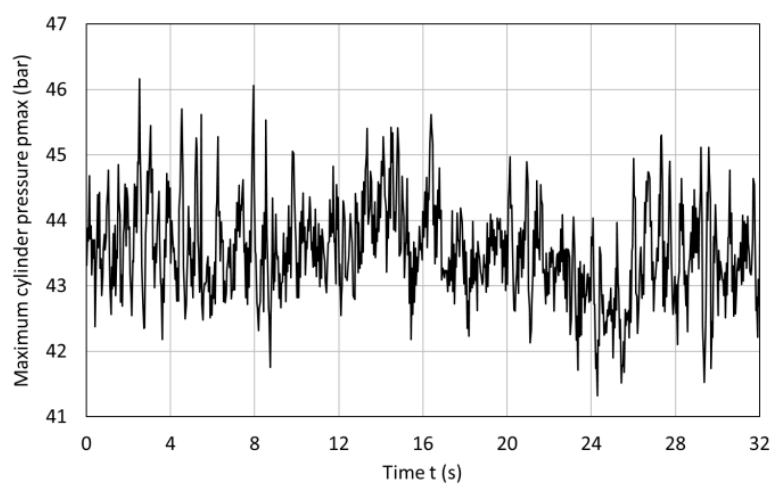

Fig. 9. Maximum cylinder pressure for operating point No. 2

The increase in the load resulted in the reduction of pressure instability in the cylinder. Its value for the 2 nd operating point varied from 41.32 to 46.16 bar. The average value of $\mathrm{p}_{\max }$ for this case was less than the value corresponding to the 1 st operating point.

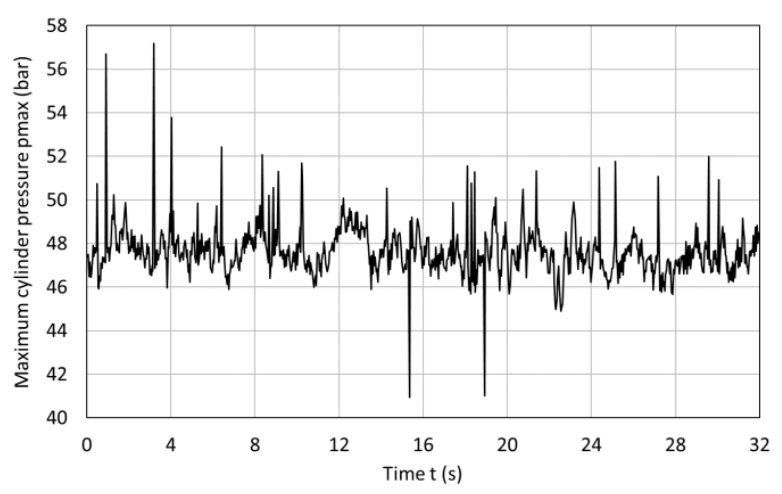

Fig. 10. Maximum cylinder pressure for operating point No. 3

Further increase in the load resulted in the occurrence of single high pressure increases. For example, the average value of $\mathrm{p}_{\max }$ for this case was 47.64 bar, and the maximum jump was 57.19 bar. The value of the maximum pressure in the cylinder changed in the range of 40.95-57.19 bar.

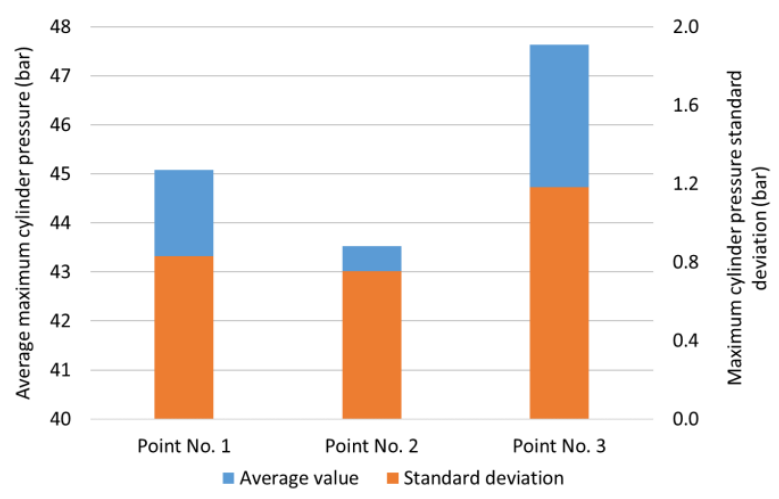

Fig. 11. Average value and standard deviation of maximum cylinder pressure
Figure 11 shows the average value of maximum cylinder pressure and standard deviation of maximum cylinder pressure for analyzed operating points. Due to unstable operation, the increase in load did not result in an increase in the average maximum cylinder pressure. For operating point No. 2, a lower value of $\mathrm{p}_{\max }$ was observed compared to point No. 1. In the case of the third operating point, the highest value of standard deviation occurred. This means a large variation of pressure during the measurement.

Based on the results of the pressure measurement, return maps for the tested engine were developed. The return map shows the relationship between the given work cycle and the next cycle for the selected engine operation parameter.

Figure 12 shows the return maps for the maximum cylinder pressure for the considered operating points.

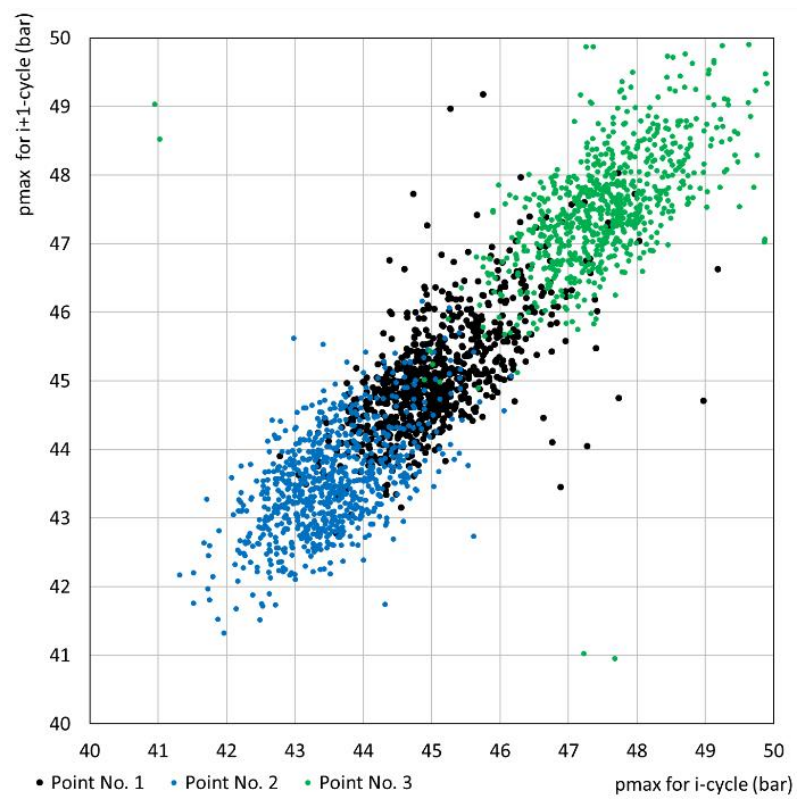

Fig. 12. $\mathrm{p}_{\max }$ return maps for the analyzed operating points

For all the work points considered, there was a significant dispersion of the measurement points. This means that the engine operation was not stable under given conditions. The distribution of points along the line confirms that the maximum pressure is unstable. At the same time, it can be concluded that the subsequent values depend on the previous values.

\section{Conclusions}

The paper presents experimental results of two-stroke opposed piston engine tests. The measurements performed on the test bench made it possible to register the pressure in one of the engine cylinders.

The recorded signal was subjected to filtration. Maximum pressure values were obtained for the analyzed operating points, which were subjected to statistical analysis. In addition, return maps for $\mathrm{p}_{\max }$ were developed.

A significant fluctuation in cylinder pressure was observed, which translated into unstable operation. The measured pressure for analyzed operating points ranged from 41 to 57 bar.

As part of further work, optimization of the injection process and control algorithm is planned. 
Acknowledgements

This work has been realized in the cooperation with The Construction Office of WSK "PZL-KALISZ" S.A." and is part of Grant
Agreement No. POIR.01.02.00-00-0002/15 financed by the Polish National Centre for Research and Development.

\section{Nomenclature}

$\begin{array}{llll}\text { CI } & \text { compression ignition } & \text { EGR } & \text { exhaust gas recirculation } \\ \text { CPBC } & \text { cylinder pressure-based control system } & \text { SI } & \text { spark ignition }\end{array}$

\section{Bibliography}

[1] HEYWOOD, J.B. Internal combustion engine fundamentals. Mcgraw-Hill Education. 1988.

[2] LAPUERTA, M., ARMAS, O., HERNÁNDEZ, J.J. Diagnosis of DI diesel combustion from in-cylinder pressure signal by estimation of mean thermodynamic properties of the gas. Applied Thermal Engineering. 1999, 19(5), 513-529. DOI: 10.1016/S1359-4311(98)00075-1

[3] LUJÁN, J.M., BERMÚDEZ, V., GUARDIOLA, C. et al. A methodology for combustion detection in diesel engines through in-cylinder pressure derivative signal. Mechanical systems and signal processing. 2010, 24(7), 2261-2275. DOI: 10.1016/j.ymssp.2009.12.012

[4] MACIÁN, V., LUJÁN, J.M., GUARDIOLA, C. et al. A comparison of different methods for fuel delivery unevenness detection in Diesel engines. Mechanical systems and signal processing. 2006, 20(8), 2219-2231. DOI: 10.1016/j.ymssp.2005.04.001

[5] BODISCO, T., BROWN, R.J. Inter-cycle variability of incylinder pressure parameters in an ethanol fumigated common rail diesel engine. Energy. 2013, 52, 55-65. DOI: 10.1016/j.energy.2012.12.032

[6] PAYRI, F., BROATCH, A., TORMOS, B. et al. New methodology for in-cylinder pressure analysis in direct injection diesel engines - application to combustion noise. Measurement Science and Technology. 2005, 16(2), 540-547. DOI: 10.1088/0957-0233/16/2/029

[7] TORREGROSA, A.J., BROATCH, A., MARTÍN, J. et al. Combustion noise level assessment in direct injection diesel engines by means of in-cylinder pressure components. Measurement Science and Technology. 2007, 18(7), 21312142. DOI: $10.1088 / 0957-0233 / 18 / 7 / 045$
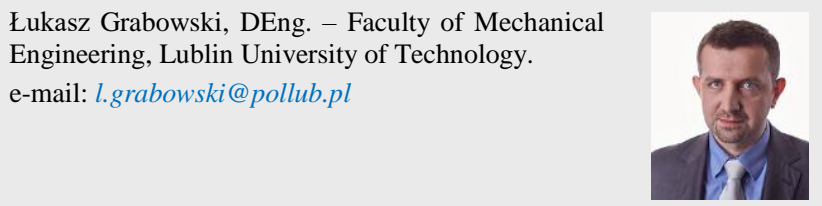

[8] SCHIEFER, D., MAENNEL, R., NARDONI, W. Advantages of diesel engine control using in-cylinder pressure information for closed loop control. SAE Technical Paper 2003-01-0364. 2003. DOI: 10.4271/2003-01-0364

[9] WILLEMS, F., DOOSJE, E., ENGELS, F. et al. Cylinder pressure-based control in heavy-duty EGR diesel engines using a virtual heat release and emission sensor. SAE Technical Paper 2010-01-0564. 2010. DOI: 10.4271/2010-010564

[10] HUSTED, H., KRUGER, D., FATTIC, G. et al. Cylinder pressure-based control of pre-mixed diesel combustion. SAE Technical Paper 2007-01-0773. 2007. DOI: 10.4271/200701-0773

[11] GU, F., JACOB, P.J., BALL, A.D. Non-parametric models in the monitoring of engine performance and condition: part 2: non-intrusive estimation of diesel engine cylinder pressure and its use in fault detection. Proceedings of the Institution of Mechanical Engineers, Part D: Journal of Automobile Engineering. 1999, 213(2), 135-143. DOI: 10.1243/ 0954407991526757

[12] GAO, Y., RANDALL, R.B. Reconstruction of diesel engine cylinder pressure using a time domain smoothing technique. Mechanical systems and signal processing. 1999, 13(5), 709-722. DOI: $10.1006 / \mathrm{mssp} .1999 .1229$

[13] TRAVER, M.L., ATKINSON, R.J., ATKINSON, C.M. Neural network-based diesel engine emissions prediction using in-cylinder combustion pressure. SAE Technical Paper 1999-01-1532. 1999. DOI: 10.4271/1999-01-1532

[14] ÇEBI, E.C., ROTTENKOLBER, G., UYAR, E. In-cylinder pressure based real-time estimation of engine-out particulate matter emissions of a diesel engine. SAE Technical Paper 2011-01-1440. 2011. DOI: 10.4271/2011-01-1440

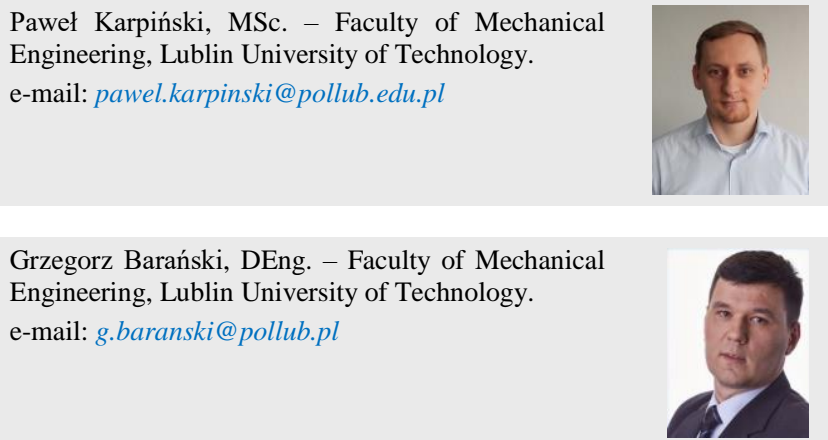

